International Journal of Biological Sciences

ISSN 1449-2288 www.biolsci.org 2008 4(3):176-183

Research Paper

CIvyspring International Publisher. All rights reserved

\title{
CO-releasing molecules (CORV-2)-liberated CO attenuates leukocytes infil- tration in the renal tissue of thermally injured mice
}

\author{
Bingwei Sun, Zhiwei Sun, Qin Jin, Xi Chen \\ Department of Burns and Plastic Surgery, Affiliated Hospital, Jiangsu University, Zhenjiang 212001, Jiangsu Province, PR \\ China
}

Correspondence to: Dr. Bing-Wei Sun, Department of Burns and Plastic Surgery, Affiliated Hospital, Jiangsu University, 438 Jiefang Rd. Zhenjiang 212001, Jiangsu Province, China. Tel: ++86 511 85082258; Fax: ++86 511 85029089; Email: sunbinwe@vip.sina.com

Received: 2008.05.30; Accepted: 2008.06.16; Published: 2008.06.16

Objective: To determine whether the CO-releasing molecule -liberated CO attenuates infiltration of leukocytes in the renal tissue of thermally injured mice.

Materials and methods: Twenty-eight mice were assigned to four groups. Mice in sham group ( $n=7)$ were underwent sham thermal injury, whereas mice in burn group $(n=7)$ received $15 \%$ total body surface area (TBSA) full-thickness thermal injury. Mice in burn+CORM-2 group $(n=7)$ underwent thermal injury followed by immediate administration of CORM-2 (8mg/ $\mathrm{kg}$, i.v.), whereas mice in burn+iCORM-2 group $(n=7)$ underwent thermal injury followed by administration of iCORM-2 (an inactive compound used as negative control). Histological alterations and granulocytes infiltration in kidney were assessed alongised PMN accumulation, activation of NF-kB, expressions of ICAM-1 and HO-1 expression in renal tissues.

Results: Treatment of thermally injured mice with CORM-2 significantly attenuated PMN accumulation and prevented activation of NF-kB in the kidney. This was accompanied by a decrease of the expression of ICAM-1 and an increase in HO-1 expression. In parallel, burn-induced granulocytes infiltration in renal tissue was markedly decreased by treatment with CORM-2.

Conclusions: CO delivered by CORM-2 attenuates leukocytes infiltration in the kidney of burned mice by interfering with NF-kB activation, protein expression of ICAM-1 and therefore suppressing endothelial cells pro-adhesive phenotype.

Key words: kidney; leukocyte infiltration; carbon monoxide; thermal injury

\section{Introduction}

Severe burn injury is known to induce the systemic inflammatory response syndrome (SIRS), which correlates with a high risk of end organ failure as seen in burn-induced acute renal injury [1,2]. Thermal injury is accompanied by complex events that exert deleterious effects on various organs, such as kidney, distant from the original burn wound. Kidney is considered to be the critical organ in the development of organ dysfunction in trauma, burn, and intensive care unit patients [3]. Following thermal injury, kidney is subjected to ischemia, and consequently, reperfusion injury occurs during burn resuscitation [4]. Renal ischemia-reperfusion results in organ injury through both tissue hypoxia and reperfusion phenomena mediated by neutrophils. Acute renal failure (ARF) is one of the well-known complications after severe burns with an extremely high incidence of death $[5,6]$.

A variety of cytokines are released into the microcirculation by neutrophils, endothelial cells, and monocytes during phases of hypoxia and reperfusion
$[7,8]$. Although the pathophysiological basis of organ damage remains unclear, there is increasing evidences that leukocytes infiltration into renal tissue exerts important roles in the acute renal failure and development of SIRS after thermal injury [9-11]. In most circumstances, ARF manifests as a part of multiorgan dysfunction syndrome and the kidney-oriented supportive therapy so far has not achieved satisfactory results [12].

Many results have suggested that endogenous carbon monoxide (CO), a by-product of inducible heme oxygenase (HO-1) can modulate inflammation. In addition, experimental evidence supports that administration of exogenous CO inhibits lipopolysaccharide(LPS)-induced production of cytokines both in vivo and in vitro, and consequently exhibits important cytoprotective and anti-inflammatory function that are beneficial for the resolution of acute inflammation [13-15].

Recently, transition metal carbonyls have been identified as CO-releasing molecules (CORMs) with the potential to facilitate the pharmaceutical use of $\mathrm{CO}$ 
by delivering it to tissues and organs [16-18]. CORMs have been shown to promote vasorelaxant effects on aortic and cardiac tissues of rats [17, 19-21], and decreased myocardial ischemia/reperfusion damage [18, 22]. Our previous studies [23, 24] have showed that burn-induced overexpression of adhesion molecules (such as ICAM-1, VCAM-1) on endothelial cells and leukocytes might contribute to liver and lung tissue injury, subsequently leading the multiple organ dysfunction syndrome (MODS). Our data also indicated that $\mathrm{CO}$ liberated by CORM-2 attenuated leukocytes sequestration in the liver and lung tissues of thermally injured mice by interfering with NF-kB activation, protein expression of ICAM-1 and therefore suppressing endothelial cells pro-adhesive phenotype.

Based on these preliminary observations, the goal of the present study was to specifically test the effects of $\mathrm{CO}$ on attenuation of leukocytes infiltration in the renal tissue of thermally injured mice using the well characterized carbon monoxide-releasing molecule, tricarbonyldichlororuthenium (II) dimmer (CORM-2) [17].

\section{Materials and methods}

Materials

Tricarbonyldichlororuthenium (II) dimer (CORM-2) was obtained from Sigma Aldrich and solubilized in dimethyl sulfoxide (DMSO) to obtain a $10 \mathrm{mM}$ stock. The chemical structure of CORM-2 is represented in Fig. 1. Inactive form of the compound (negative control) was also used in some experiments and it was prepared as follows: CORM-2 was 'inactivated' (iCORM-2) by adding the compound to DMSO and leaving it for $18 \mathrm{~h}$ at $37^{\circ} \mathrm{C}$ in a $5 \% \mathrm{CO}_{2}$ humidified atmosphere to liberate $\mathrm{CO}$. The iCORM-2 solution was finally bubbled with nitrogen to remove the residual $\mathrm{CO}$ present in the solution. Polyclonal or monoclonal antibodies against ICAM-1 and HO-1 were purchased from Santa Cruz Biotechnology Inc. All other chemicals were reagent grade and obtained from Sigma unless otherwise stated.

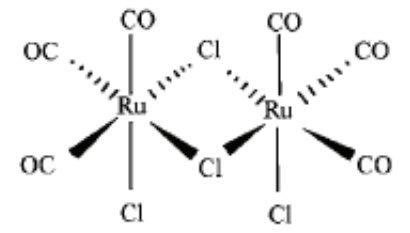

Tricarbonyldichloro ruthenium(II) dimer $\left[\mathrm{Ru}(\mathrm{CO})_{3} \mathrm{Cl}_{2}\right]_{2}$

Fig. 1. Chemical structure of CORM-2.

Animal and Burn Protocol

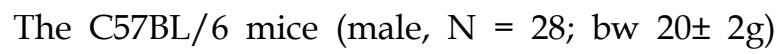

were fed a standard laboratory diet and water ad libitum. Mice were assigned to four groups. Mice in sham group $(n=7)$ were underwent sham thermal injury, whereas mice in burn group $(n=7)$ received $15 \%$ total body surface area (TBSA) full-thickness thermal injury, mice in CORM-2 group $(n=7)$ underwent the same thermal injury with immediate administration of CORM-2 (8mg/kg, i.v.), and mice in burn+iCORM group $(n=7)$ underwent the same injury with immediate administration of iCORM-2 with the same dose as CORM-2 group. This negative control (iCORM-2) was performed to assess whether the effects observed were due to the CO liberated by the CORMs or caused by other components of the molecules. The concentration of CORM-2 used in the present study was based on a previous report in of the use of this compound in mice[25] and the preliminary experiments in our lab by measuring dynamic $\mathrm{COHb}$ levels and peak levels which did not averaged $15 \pm 5 \%$ above normal levels. The experimental protocol was approved by The Council on Animal Care at Jiangsu University on the protection and the welfare of animals. Under anesthesia of spontaneous inhalation of isoflurane-N2O (Abbott Laboratories, Missisauga, ON, Canada) in a $60 \%$ oxygen $-40 \%$ nitrogen mixture, the dorsum of each mouse was shaved and the animal was subjected to $15 \%$ TBSA full-thickness thermal injury as previously described $[26,27]$. Sham animals were immersed in a room temperature water bath. All animals were resuscitated intraperitoneally with $1.5 \mathrm{ml}$ saline immediately after thermal (or sham) injury. No wound care was required for the burn wounds. This burn method achieves a histologically proven, full-thickness scald injury. The animals were sacrificed at $24 \mathrm{~h}$ after experimental manipulation.

\section{Histological analysis}

The kidney specimens harvested from experimental animals were immersed in $4 \%$ formaldehyde solution at $24 \mathrm{~h}$ after thermal injury. The tissues were embedded in paraffin wax, serially sectioned, and stained with hematoxylin- eosin. Renal morphologic characteristics were evaluated under light microscope. Tubular injury was assessed in sections using a semiquantitative scale [28] in which the percentage of cortical tubules showing epithelial necrosis was assigned a score: $0=$ normal; $1=<10 \% ; 2=10-25 \% ; 3=26-75 \%$; $4=>75 \%$. Sections were scored independently by two investigators who were blinded to the treatment of the animal.

\section{Renal function}

Renal function was assessed by measurements of blood urea nitrogen (BUN; VITROS DT60II Chemistry slides, Orthoclinical Diagnostics) and serum creatinine 
(DZ072B, Diazyme Labs).

\section{MPO activity}

MPO activity was measured in renal tissue in a procedure similar to that documented by Hillegas et al [29]. Tissue samples were homogenized in $50 \mathrm{mM}$ potassium phosphate buffer ( $\mathrm{pH}$ 6.0), and centrifuged at $10,000 \mathrm{~g}$ (10min); pellets were suspended in $50 \mathrm{mM} \mathrm{PB}$ containing $0.5 \%$ hexadecyltrimethylammonium bromide (HETAB). After sonication, the samples were centrifuged at $10,000 \mathrm{~g}$ for $10 \mathrm{~min}$. Aliquots $(0.3 \mathrm{ml})$ were added to $2.3 \mathrm{ml}$ of reaction mixture containing 50 $\mathrm{mM} \mathrm{PB}$, o-dianisidine, and $20 \mathrm{mM} \mathrm{H}_{2} \mathrm{O}_{2}$ solution. One unit of enzyme activity was defined as the amount of MPO present that caused a change in absorbance measured at $460 \mathrm{~nm}$ for $3 \mathrm{~min}$. MPO activity was expressed as U/g tissue.

\section{Western blot analysis}

Extract preparations and SDS-PAGE was performed as described previously [23, 24]. Blocked membranes were incubated in primary antibody specific for mouse ICAM-1 and HO-1 at concentrations of 1:1000 and 1:5000 dilution respectively in TBST overnight at $4^{\circ} \mathrm{C}$. Then the membranes were washed and probed with horseradish peroxidase-conjugated secondary antibody (Amersham Pharmacia Biotech, Inc.) for $1 \mathrm{~h}$ at room temperature. Chemiluminescence detections were performed with the Amersham enhanced chemiluminescence detection kit according to the manufacturer's instructions.

Preparation of nuclear extracts and electrophoretic mobility shift assay (EMSA)

Nuclear proteins from renal tissues were extracted using the method of our laboratory as described previously [30,31]. For EMSA, $5 \mu \mathrm{g}$ of total nuclear proteins was incubated with 1.0 pmol of double-stranded $\quad \gamma\left[{ }^{32} \mathrm{P}\right]$ ATP end-labeled oligonucleotides containing consensus binding sequences for NF-kB (sense strand 5'-AGGGACTTTCCGCTGGGGA CTTTCC-3') in a binding buffer (10mM HEPES, $\mathrm{pH}$ $7.9,80 \mathrm{mM} \mathrm{NaCl}, 3 \mathrm{mM} \mathrm{MgCl} 2,0.1 \mathrm{mM}$ EDTA, $1 \mathrm{mM}$ DTT, 1mM PMSF, and 10\% glycerol) as described previously [32]. Samples were incubated for $30 \mathrm{~min}$ at room temperature and then run through a $4 \%$ nondenaturing polyacrylamide gel $(0.5 \times \mathrm{TBE}$ buffer $)$ at $280 \mathrm{~V}$ for $1 \mathrm{~h}$. Gels were dried and then exposed to X-ray film (Kodak) for $4-6 \mathrm{~h}$ in cassettes at $-80^{\circ} \mathrm{C}$. Signal detection and quantification were performed by computer-assisted densitometry.

\section{Statistical analysis}

All of the values are presented as means \pm SD. Statistical analysis was performed with the use of ANOVA and Student's t-test for the comparisons. A value of $P<0.05$ was considered to be statistically significant.

\section{Results}

Histology

Histological analysis showed that renal sections from sham mice demonstrated the normal architectures (Fig.2, A), while thermal injury induced severe edema and infiltration of the inflammatory cells and granulocytes (Fig.2, B). In vivo administration of CORM-2 (8mg/ kg, i.v.), granulocytes infiltration was significantly decreased (Fig.2, C). However CORM-2 did not improve the edema induced by thermal injury. Tubular injury was assessed in sections using a semiquantitative scale. As shown in Fig.2 (D), the percentages of epithelial necrosis in cortical tubules increased in burn group, while this necrosis was markedly improved after in vivo administration of CORM-2.

\section{Renal function}

To examine the role of CORM-2 in burn-induced kidney dysfunction, CORM-2 was administered to thermally injured mice. As shown in Fig. 3, thermal injury produced severe renal dysfunction. Administration of CORM-2 significantly reduced both BUN $(64.3 \pm 11.9$ vs $32.6 \pm 10.8 \mathrm{mg} / \mathrm{dl}, P<0.05)$ and creatinine $(1.9 \pm 0.3$ vs $0.6 \pm 0.1 \mathrm{mg} / \mathrm{dl}, P<0.05)$ levels compared with burn group. The improvement of renal functions was accompanied by less severe histological damage and reduced leukocytes infiltration. No significance shown between burn group and burn+iCORM group.

Effect of CORM-2 on MPO activity in kidney of thermally injured mice

In order to determine whether burn-induced increase in PMN accumulation in the kidney was effectively prevented by CORM-2, the activity of MPO, an enzyme in azurophilic granules of neutrophils, was assessed. Extracts of the renal samples were examined for contents of MPO at $24 \mathrm{~h}$ after thermal injury. The mean MPO levels markedly increased in burn mice (32.8 \pm 3.3 vs $11.9 \pm 1.2$ unit/g tissue, $\mathrm{P}<0.01$ ) compared with sham group. Administration of CORM-2 significantly decreased MPO activity (21.6 \pm 5.4 vs $32.8 \pm 3.3$ unit/g tissue, $\mathrm{P}<0.05$ ) compared with burn group. No significance shown between burn group and burn+iCORM group.

Effect of CORM-2 on expressions of HO-1 and ICAM-1 (Western Blot) in the kidney of thermally injured mice

At $24 \mathrm{~h}$ after a 15\% TBSA full-thickness thermal injury, the expressions of HO-1 and ICAM-1 in renal tissues significantly increased compared to the sham animals. In vivo administration of CORM-2, expression of ICAM-1 was significantly decreased (Fig. 4, A 
and C), while expression of HO-1 was more significantly increased compared to burn group (Fig. 4, A and B). No significance shown between burn group and burn+iCORM group.

Effect of CORM-2 on activity of NF- $k B$ in the kidney of thermally injured mice

Binding activities of nuclear protein to the radio-
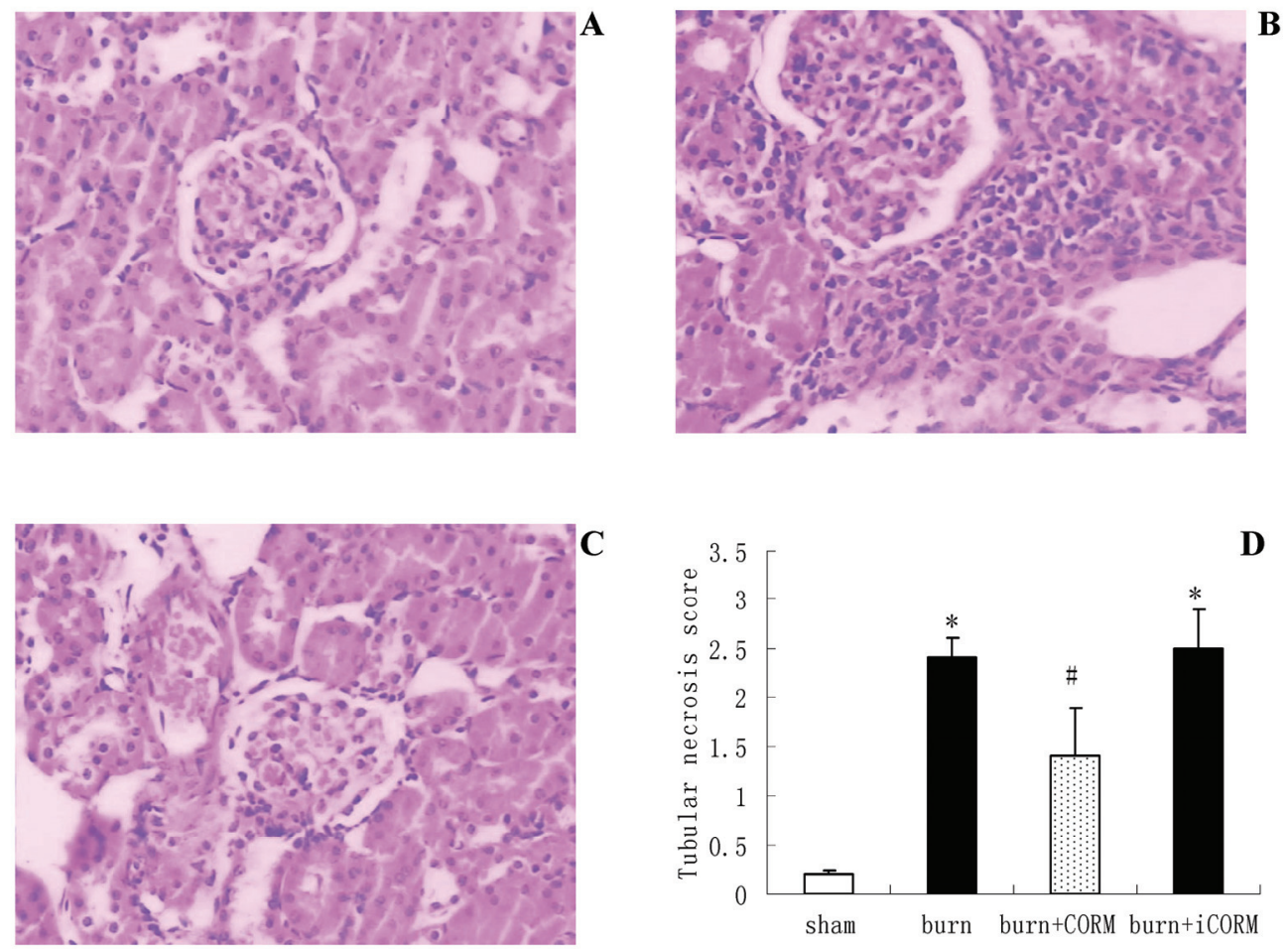

Fig.2. Effect of CORM-2 on renal injury in thermally injured mice. Mice were injected (i.v.) with CORM-2 (8 mg/kg) immediately after thermal injury. Renal sections from sham mice showed the normal architectures (A), while that from thermally injured mice showed severe edema and inflammatory cells infiltration (B). On the contrary, renal sections from burn mice that had received administration of CORM-2 (C) showed significant decrease of granulocytes infiltration. Semiquantitative scoring of histological injury (D) was described in MATERIALS AND METHODS. Magnification: $\times 200$. ${ }^{*} P<0.05$ vs. sham; $\# P<0.05$ vs. burn group. The figure is representative of five experiments performed on different experimental days.

A

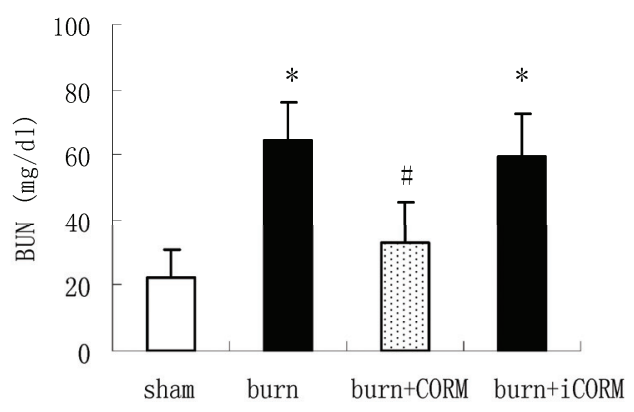

labeled consensus binding sequences of NF-kB was assessed by EMSA. At $24 \mathrm{~h}$ after a $15 \%$ TBSA full-thickness thermal injury, NF-kB activation in the renal tissues was markedly increased and this activity was markedly inhibited by in vivo administration of CORM-2 (Fig. 5).

\section{B}

D 
$\mathbf{A}$
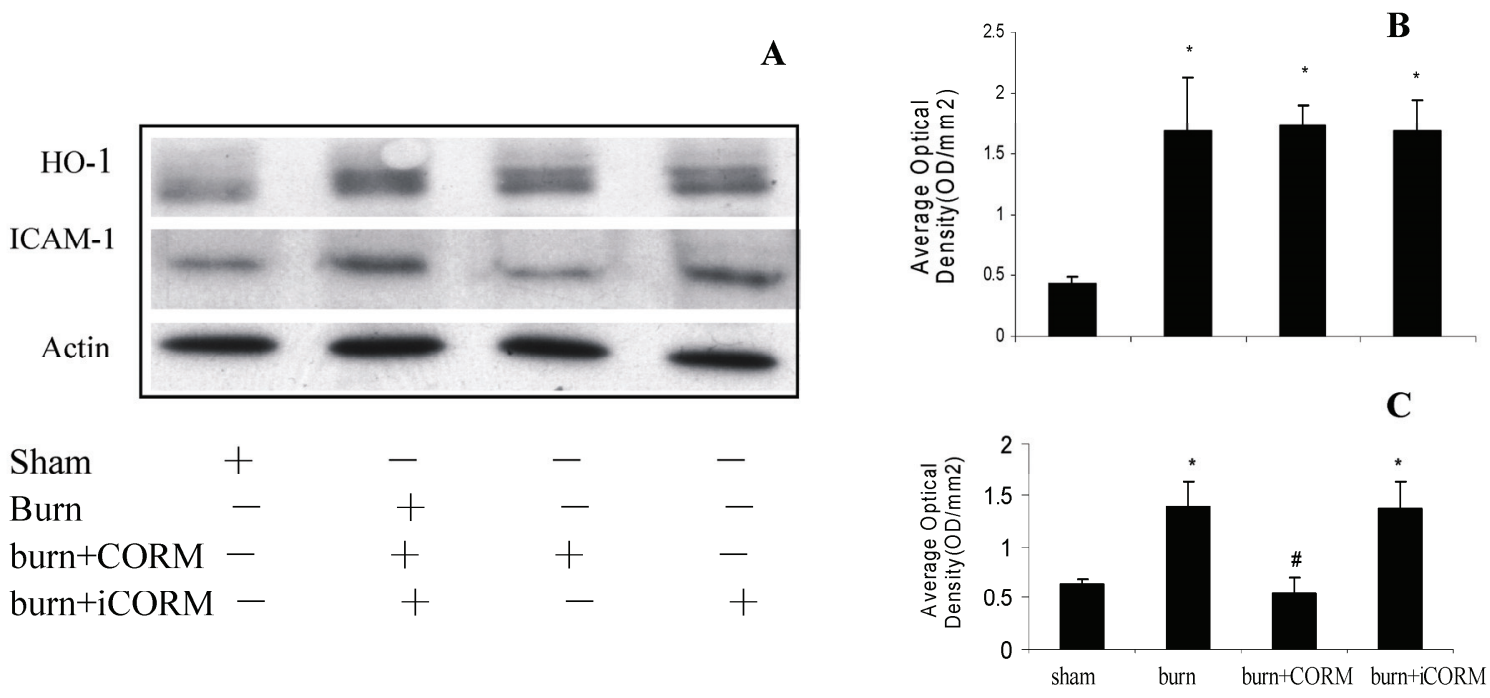

Fig.4. Effect of CORM-2 on protein expressions of ICAM-1 and HO-1 in the renal tissue of thermally injured mice. Protein expressions of ICAM-1 and HO- 1 were performed by western blotting at $24 \mathrm{~h}$ after thermal injury. A representative experiment was shown in A. The quantitative results (average optical density) of three experiments were shown in B (HO-1) and C (ICAM-1). $* P$ $<0.05$ vs. sham; $\# P<0.05$ vs. burn group.

$\mathbf{A}$

B

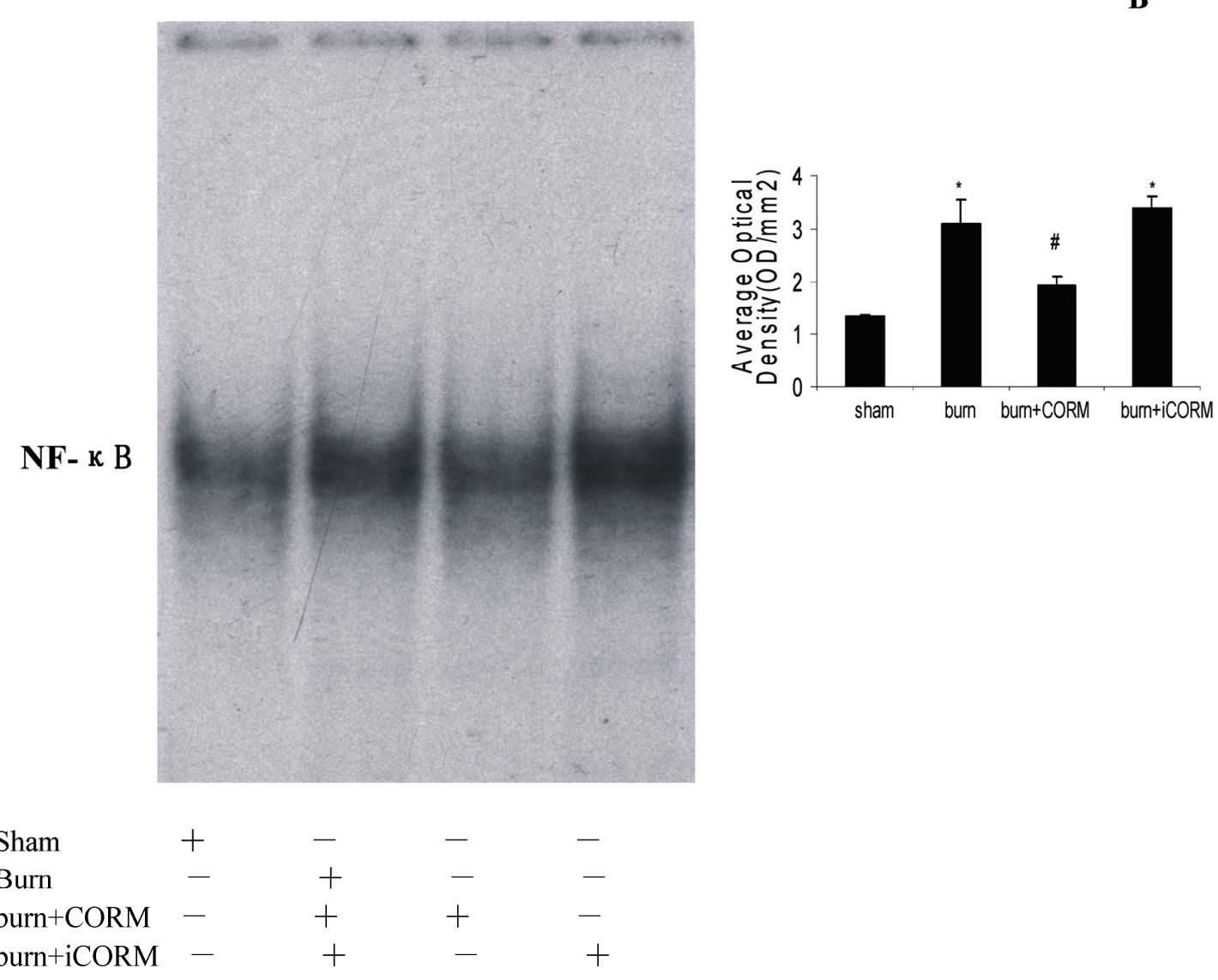

Fig.5. Effect of CORM-2 on NF-kB activation in the renal tissue of thermally injured mice (EMSA). Measurement of NF-kB activity was performed by mobility shift assay (EMSA) with ${ }^{32} \mathrm{P}$-labeled NF-KB probe and $5 \mu \mathrm{g}$ of nuclear extracts from renal tissues of experimental mice at $24 \mathrm{~h}$ after thermal injury. The NF-KB activation in kidney of thermally injured mice was markedly increased and this increase was inhibited by in vivo administration of CORM-2. A representative experiment was shown in A, and quantitative results (average optical density) of three experiments were shown in $\mathrm{B}$. ${ }^{*} P<0.05$ vs. sham; $\# P<0.05$ vs. burn group. 


\section{Discussion}

Recently CORMs that have the ability to release $\mathrm{CO}$ in biological systems have been identified and synthesized [16]. CORM-2, a DMSO- soluble CORM, has exhibited anti-inflammatory actions in an in vitro model of LPS-stimulated murine macrophages [33] and renoprotective effects in models of ischemia-reperfusion injury [34] and cisplatin-induced nephrotoxicity [35]. In the present study we report that $\mathrm{CO}$ delivered by CORM-2 exerts a protective effect against the pathological changes of kidney and reduction of the levels of BUN and creatinine caused by thermal injury. Importantly, this exogenous $\mathrm{CO}$ is effective at inhibiting the activation of NF-KB and expression of ICAM-1. Thus, we propose that CORM-2 contributes to the attenuation of leukocytes infiltration in the renal tissue after burn challenge.

Myeloperoxidase (MPO) is an enzyme that is found predominantly in the azurophilic granules of polymorphonuclear leukocytes (PMN). Tissue MPO activity is frequently utilized to estimate tissue PMN accumulation in inflamed tissues and correlates with the number of PMN determined histologically in tissues [36]. In the present study, we found that MPO activity in renal tissue was markedly elevated after thermal injury and this increase was significantly attenuated after in vivo administration of CORM-2. This indicated that CORM-2 effectively prevented PMN chemotaxis and infiltration in renal tissue after thermal injury, consequently decreasing the production of oxidants, and reducing tissue oxidant-mediated injury.

The interaction between leukocytes and endothelial cells plays a major role in the pathogenesis of inflammation, tissue repair, or self-tissue damage [37, 38]. Prevention of leukocytes infiltration in tissue would be extremely important clue to reduce tissue injury and improve immune function. This interaction was governed by adhesion molecules such as ICAM-1 and VCAM-1. ICAM-1, mediating leukocytes adhesion, presences correlates with infiltration of leukocytes into inflammatory lesions $[39,40]$. It seems to be the initial marker of inflammatory reactions and is involved in the acute inflammatory reaction following burn injury [41-43]. The present results showed that at $24 \mathrm{~h}$ post-burn, the expression levels of ICAM-1 in renal tissue were markedly upregulated. In vivo administration of CORM-2 was able to inhibit the upregulation of ICAM-1 induced by thermal injury. Our findings here strongly indicated that CORM-2 appeared to be related to inhibit leukocytes activation and adhesion, and consequently might effectively decrease inflammatory response in the kidney induced by burn injury.
Heme oxygenase $(\mathrm{HO})$ is a rate-limiting enzyme that is responsible for the catabolism of heme into bilirubin, free iron, and CO. HO- 1 isoform is a stress-responsive protein that is induced by various stimuli. The adaptive response of $\mathrm{HO}-1$ to various stimuli suggests that HO-1 may play an important role in protecting against inflammatory response and oxidative injury. Works from other laboratories have shown that the up-regulation of endogenous HO-1 ameliorated inflammatory responses and/or tissue damage [44]. In this study, we found that HO-1 was significantly upregulated by thermal injury. Interestingly, the expression of HO-1 in the kidney of thermally injured mice with application of CORM-2 was more significantly increased compared to burn mice. This result indicated that not only major burn injury, a severe trauma, might significantly induce the expression of HO-1, but also the increase of HO-1 expression could be further enhanced by the in vivo administration of CORM-2.

The nuclear factor $\mathrm{kB}(\mathrm{NF}-\mathrm{kB})$ family members control transcriptional activity of various promoters of proinflammatory cytokines, cell surface receptors, transcription factors, and adhesion molecules that are involved in renal inflammation [45]. Stimuli like oxidative stress, cytokines (interleukin-1, interleukin-6, $\mathrm{TNF}-\alpha$ ), bacteria, and viruses can release NF-kB from their inactive cytoplasmic form to the nucleus. Thermal injury has been known to induce hepatic NF-kB activation associated with hepatic cell apoptosis and proliferation, but its effect on NF- $\mathrm{kB}$ activation of kidney has never been clarified. Previously, using a thermal injury model in mice, we showed that CORM-2 plays a pivotal role in inhibition of NF- $\mathrm{KB}$ activity in the liver, subsequently decreased the hepatocellular secretion of inflammatory cytokines and burn-related hepatic dysfunction. In this study, NF-kB activity in kidney was elevated by thermal injury while it was markedly inhibited by in vivo administration of CORM-2. These data indicated that CORM-2 exhibited, at least partly, an important role in inhibition of NF-kB activity in kidney of thermally injured mice.

In conclusion, the present studies serve to clarify the role of CORM-2, one of the novel CO-releasing molecules, on the mechanisms of attenuation of leukocytes infiltration in renal tissues in thermally injured mice. Our findings indicated that $\mathrm{CO}$ delivered by CORM-2 modulates renal inflammation in burned mice by interfering with NF-kB activation, protein expressions of ICAM-1 and HO-1 and therefore suppressing endothelial cell pro-adhesive phenotype. The data support previous reports showing beneficial effects of CO-RMs in modulating leukocyte-endothelial 
interactions in a model of inflammation [46] as well as renoprotective actions by CO-RMs in models of ischemia-reperfusion injury [34] and neprotoxicity [35]. Further studies should be conducted in these issues to determine the detail mechanisms of anti-inflammatory effects mediated by CORMs.

\section{Acknowledgements}

We thank professor Gediminas Cepinskas (University of Western Ontario) for the technical assistance. This work was supported by National Natural Science Foundation of China, No.30772256.

\section{Conflict of Interests}

The authors have declared that no conflict of interest exists.

\section{References}

[1] Sittig K, Deitch EA. Effect of bacteremia on mortality after thermal injury. Arch Surg. 1988;123:1367-70.

[2] Housenger TA, Brinkerhoff C, Warden GD. The relationship between platelet count, sepsis and survival in pediatric burn patients. Arch Surg. 1993;128:65-7.

[3] Chrysopoulo MT, Jeschke MG, Dziewulski P, et al. Acute renal dysfunction in severely burned adults. J Trauma. 1999;46:141-4.

[4] Ward PA, Till GO. Pathophysiologic events related tothermal injury of skin. J Trauma. 1990;30 (Suppl 12):S75-9.

[5] Holm C, Horbrand F, von Donnersmarck GH, et al. Acute renal failure in severely burned patients. Burns. 1999;25:171-8.

[6] Kim GH, Oh KH, Yoon JW, et al. Impact of burn size and initial serum albumin level on acute renal failure occurring in major burn. Am J Nephrol. 2003;23:55-60.

[7] Wyble CW, Desai TR, Clark ET, et al. Physiologic concentrations of TNFa and IL-1b released from reperfused human intestine upregulate E-Selectin and ICAM-1. J Surg Res. 1996;63:333-8.

[8] Kuwabara Y, Kato T, Sato A, et al. Prolonged Effect of Leukocytosis on Reperfusion Injury of Rat Intestine: Real-Time ATP Change Studied Using 31P MRS. J Surg Res. 2000;89:38-42.

[9] Sener G, Sehirli AO, Satiroğlu H, et al. Melatonin improves oxidative organ damage in a rat model of thermal injury. Burns. 2002;28:419-25.

[10] Horton JW. Free radicals and lipid peroxidation mediated injury in burn trauma: the role of antioxidant therapy. Toxicology. 2003;189:75-88.

[11] Sun Z, Wang X, Lasson AE, et al. Effects of inhibition of PAF, ICAM- 1 and PECAM- 1 on gut barrier failure caused by intestinal ischemia and reperfusion. Scand J Gastroenterol. 2001;36:55-65.

[12] Triolo G, Mariano F, Stella M, et al. Dialytic therapy in severely burnt patients with acute renal failure. G Ital Nefrol. 2002;19:155-9.

[13] Hayashi S, Takamiya R, Yamaguchi T, et al. Induction of heme oxygenase- 1 suppresses venular leukocyte adhesion elicited by oxidative stress. Role of bilirubin generatedby the enzyme. Circ Res. 1999;85:663-71.

[14] Lee T, Chau LY. Heme oxygenase-1 mediates the anti-inflammatory effect of interleukin-10 in mice. Nat Med. 2002;8:240-6.

[15] Otterbein LE, Soares M., Yamashita K, et al. Heme oxygenase-1: unleashing the protective properties of heme. Trends Immunol. 2003;24:449-55.

[16] Motterlini R, Mann BE, Johnson TR, et al. Bioactivity and pharmacological actions of carbon monoxide-releasing molecules. Curr Pharm Des. 2003;9:2525-39.
[17] Motterlini R, Clark JE, Foresti R, et al. Carbon Monoxide-Releasing Molecules: Characterization of Biochemical and Vascular Activities. Circ Res. 2002;90:e17-24.

[18] Clark JE, Naughton P, Shurey S, et al. Cardioprotective Actions by a Water-Soluble Carbon Monoxide-Releasing Molecule. Circ Res. 2003;93:e2-8.

[19] Motterlini R, Sawle P, Bains S, et al. CORM-A1: a new pharmacologically active carbon monoxide-releasing molecule. FASEB J. 2005;19:284-6.

[20] Johnson TR, Mann BE, Clark JE, et al. Metal carbonyls: a new class of pharmaceuticals? Angew Chem Int Ed Engl. 2003;42:3722-9.

[21] Foresti R, Hammad J, Clark JE, et al. Vasoactive properties of CORM-3, a novel water-soluble carbon monoxide-releasing molecule. Br J Pharmacol. 2004; 142: 453-60.

[22] Guo Y, Stein AB, Wu WJ, et al. Administration of a Coreleasing molecule at the time of reperfusion reduces infarct size in vivo. Am J Physiol Heart Circ Physiol. 2004;286:H1649-53.

[23] Sun BW, Zhao-Yong Chen, et al. Attenuation of Leukocytes Sequestration by CO-releasing Molecules -liberated $\mathrm{CO}$ in the Liver of Thermal Mice. J Burn Care Res. 2007;28:173-81.

[24] Sun BW, Sun H, Liu C, et al. Role of CO-releasing molecules (CORM-2)-liberated $\mathrm{CO}$ in attenuating leukocytes sequestration and inflammatory responses in the lung of thermally injured mice. J Surg Res. 2007;139:128-35.

[25] Steina AB, Guoa Y, Tana W, et al. Administration of a CO-releasing molecule induces late preconditioning against myocardial infarction. J Mol Cell Cardiol. 2005;38:127-34.

[26] Faunce DE, Llanas JN, Patel PJ, et al. Neutrophil chemokine production in the skin following scald injury. Burns. 1999;25:403-7.

[27] Rana SN, Li X, Chaudry IH, et al. Inhibition of IL-18 reduces myeloperoxidase activity and prevents edema in intestine following alcohol and burn injury. J Leukoc Biol. 2005;77:719-28.

[28] Rabb H, Daniels F, O_Donnell M, et al. Pathophysiological role of $\mathrm{T}$ lymphocytes in renal ischemia-reperfusion injury in mice. Am J Physiol Renal Physiol. 2000;279:F525-31.

[29] Hillegas LM, Griswold DE, Brickson B, et al. Assessment of myeloperoxidase activity in whole rat kidney. J Pharmacol Methods. 1990;24:285-95.

[30] Lush CW, Cepinskas G, Kvietys PR. Regulation of intestinal nuclear factor-kB activity and E-selectin expression during sepsis: a role for peroxynitrite. Gastroenterology. 2003;124:118-28.

[31] Cepinskas G., Lush CW, Kvietys PR. Anoxia/reoxygenationinduced tolerance with respect to polymorphonuclear leukocyte adhesion to cultured endothelial cells - A nuclear factor-kappa B-mediated phenomenon. Circ Res. 1999;84:103-12.

[32] Bielinska A, Shivdasani RA, Zhang L, et al. Regulation of gene expression with double-stranded phosphorothioate oligonucleotides. Science. 1990;250:997-1000.

[33] Sawle P, Foresti R, Mann BE, et al. Carbon monoxide-releasing molecules (CO-RMs) attenuate the inflammatory response elicited by lipopolysaccharide in RAW264.7 murine macrophages. British J Pharma. 2005;145:800-10.

[34] Sandouka A, Fuller BJ, Mann BE, et al. Treatment with $\mathrm{CO}-\mathrm{RMs}$ during cold storage improves renal function at reperfusion. Kidney Int. 2006;69: 239-47.

[35] Tayem Y, Johnson TR, Mann BE, et al. Protection against cisplatin-induced nephrotoxicity by a carbon monoxide-releasing molecule. Am J Physiol Renal Physiol. 2006; 290: F789 - 94.

[36] Bradley PP, Priebat DA, Christensen RD, et al. Measurement of cutaneous inflammation. Estimation of neutrophil content with an enzyme marker. J Invest Dermatol. 1982;78:206-9.

[37] Cioffi WC, Burleson DG, Pruitt BA. Leukocyte responses to injury. Arch Surg. 1992;112:860-5.

[38] Arturson G. Pathophysiology of the burn wound and pharma- 
cological treatment. The Rudi Hermans Lecture, 1995. Burns. 1996;22:255-74.

[39] Defazio G, Nico B, Trojano M. et al. Inhibition of protein kinase C counteracts TNF-a-induced ICAM-1expression and fluid phase endocytosis on brain microvascular endothelial cells. Brain Res. 2000;863:245-8.

[40] Rahman A, True AL, Anwar KN, et al. Gaq and Gbg regulate PAR-1 signaling of thrombin-induced NF-KB activation and ICAM-1 transcription in endothelial cells. Circ Res. 2002;91:398-405.

[41] Mileski WJ, Burkhart D, Hunt JL, et al. Clinical effects of inhibiting leukocyte adhesion with monoclonal antibody to intercellular adhesion molecule-1 (enlimomab) in the treatment of partial-thickness burn injury. J Trauma. 2003;54:950-8.

[42] Deveci M, Eski M, Sengezer M, et al. Effects of cerium nitrate bathing and prompt burn wound excision on IL-6 and TNF-a levels in burned rats. Burns. 2000;26:41-5.

[43] Cuschieri J, Gourlay D, Garcia I, et al. Modulation of ndotoxin-induced endothelial activity by microtubule depolymerization. J Trauma. 2003;54:104-13.

[44] Attuwaybi BO, Kozar RA, Moore-Olufemi SD, et al. Heme oxygenase-1 induction by hemin protects against gut ischemia/reperfusion injury. J Surg Res. 2004;118:53-7.

[45] Hierholzer C, Kalff JC, Billiar TR, et al. Induced nitric oxide promotes intestinal inflammation following hemorrhagic shock. Am J Physiol Gastrointest Liver Physiol. 2004;286:G225-G233.

[46] Urquhart P, Rosignoli G, Cooper D, et al. Carbon Monoxide-Releasing molecules Modulate Leukocyte-Endothelial Interactions under Flow. J Pharmacol Exp Ther. 2007; 321: 656-62. 